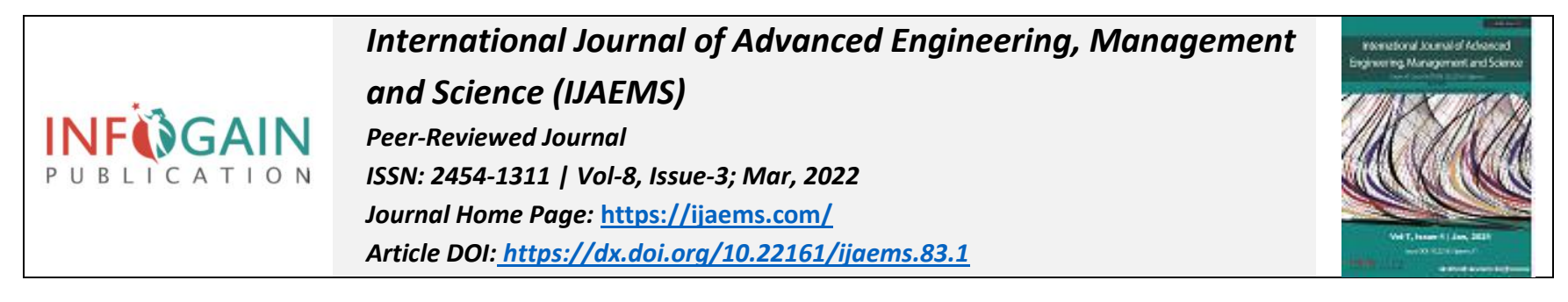

\title{
The impact of Psychological Empowerment and Organizational Justice on Perceived Organizational Performance
}

\author{
Dr. Ahmad Fathulla Ahmad \\ Aynda Private Technical Institute-Business Administration, Erbil, Iraq \\ ahmadfathullaahmad@gmail.com
}

Received: 16 Feb 2022; Received in revised form: 18 Feb 2022; Accepted: 22 Feb 2022; Available online: 3 March 2022

\begin{abstract}
The study aimed to investigate the influence of psychological empowerment and organizational justice on perceived organizational performance at public sectors in Kurdistan region of Iraq. The research provided empirical evidence regarding the role of psychological empowerment and organizational justice on perceived organizational performance. The current study applied quantitative research, a questionnaire was used to collected data from the participants (employees, supervisors, and managers) from public sector in Kurdistan region of Iraq. The sample size for the current study was 114 units. The study developed two research hypotheses to measure the current study. The findings revealed that the first research hypothesis was supported which stated that psychological empowerment has a positive and significant influence on perceived organizational performance at public sector in Kurdistan region of Iraq, furthermore the second research hypothesis was supported which stated that organizational justice has a positive and significant influence on perceived organizational performance at public sector in Kurdistan region of Iraq. However, it was found that the highest value was for the psychological empowerment effect on perceived organizational performance.
\end{abstract}

Keywords-Organizational Justice, Psychological Empowerment, Organizational Performance.

\section{INTRODUCTION}

Organizations are currently confronted with challenges such as downsizing, rightsizing, restructuring, privatization, and technological advancement (Maan et al., 2020). These business changes have increased the unemployment rate and unethical practices in organizations, particularly in the context of the KRG (Suifan et al., 2020). Similarly, Yogalakshmi\& Suganthi,(2020) has observed an increase in injustice and corruption in the KRG. Furthermore, these business changes have increased job insecurity, injustice, distrust, job dissatisfaction, and performance decline (Farooqi et al., 2019). In today's dynamic business environment, stiff business competition and a high unemployment rate have an impact on employee performance and health at work (Arefinet al., 2019).

This article can be downloaded from here: $w w w . i j a e m s . c o m$
The today 's business environment is complex, unpredictable, and chaotic (Tran \& Choi, 2019). In this regard, this study seeks to investigate organizational practices and policies that benefit both employers and employees, lead to sense and meaning making at work, and emphasize overall employee upliftment and learning (Aggarwal et al., 2018). As a result, this study considers the KRG organizational setting, which includes organizations of local origin as well as multinational corporations operating in the KRG and employing KRG workers. Performance is defined as (a) the way something or someone functions, operates, or behaves; (b) the way someone does a job, as measured by its effectiveness; and (c) the act of accomplishing something, such as a task or action. Similarly, job performance is a complex concept that includes both task-related and contextual performance factors, as well as the importance of social skills as a predictor of job performance. The extent to which an 
employee meets the overall performance expectations is defined as job performance (Aggarwal et al., 2020). Job performance, as defined by Chegini et al., (2019), is a set of behaviors that are under an individual's control and affect the goals of the employing organization. Furthermore, Loes \& Tobin, (2020), defined job performance as a function that an individual can successfully perform within the constraints and resources that are normally available. The key to developing and improving employees' job performance is identifying the various factors influencing their performance in organizations. Employees in the public sector face a variety of issues unique to their industry, such as low pay, high turnover, and issues with job motivation and performance. Similarly, some studies have found that employees in the public sector have a high turnover rate due to low pay, heavy workloads, poor job performance and learning, and a lack of organizational justice (Khalid et al., 2018). Numerous studies have been conducted to investigate the relationship between job performance, organizational justice, psychological empowerment, and organizational learning in various types of organizations (Asgari et al., 2020). However, the combined effects of organizational justice, psychological empowerment, and organizational learning on the performance of public sector employees had not previously been studied. Examining the root causes of job performance and researching the effects of organizational justice, psychological empowerment, and organizational learning on job performance can provide some understanding of problems with public sector employees as well as potential solutions (Cugueró-Escofet et al., 2019).

Over the last decade, the concept of public sector empowerment has emerged in the context of higher education (Akram et al., 2020). This is due to the benefits it provides to both the public sector and its employees (Waheed et al., 2018). Empowering human resources is regarded as a critical component in the success and achievement of such higher educational institutions in the public sector, as it is in any other workplace. What makes empowerment even more important is that educational institutions may not be able to survive and thrive in the absence of competent and committed staff (AlKahtani et al., 2021). Similarly, Psychological empowerment is an essential component of every organization, and awareness of the importance of $\mathrm{OJ}$ is growing in most organizations in order to encourage positive employee behavior. Psychological empowerment is regarded as one of the key elements and factors contributing to overall organizational effectiveness and success in a highly competitive environment (Fragkos et al., 2020). Furthermore, empowerment is one of the most effective ways to improve performance positive attitudes toward their work, including psychological empowerment (Chung, 2018).

A long-term employment bond consists of positive social exchange approaches in the employee-employer relationship, whereby both parties' needs are met (Hamza et al., 2021). The employer is concerned about the employees' devotion, engagement, and trustworthiness toward them in the exchange relationship, while the employees are concerned about whether their employer is keeping their promises by caring for their well-being (Lyu et al., 2019). Ali et al., (2021), stated in their research associates developed the theory of organizational support and the construct of organizational justice in using social exchange theory. Organizational justice is defined as employees' perceptions of the extent to which their contributions at organizations are valued, implying that their associated well-being is fully considered. According to the organizational support theory, individuals form POP, a universal belief that their employer has a favorable or unfavorable attitude toward them. Literature also confirms that individuals' organizational justice helps them to increase their obligations toward organizations in order to reciprocate favorably. They also want to meet their socioemotional needs and incorporate organizational affiliation into their social identity (Farid et al., 2019). Furthermore, existing research indicates that individuals' organizational justice improves both in-role performance such as goal attainment and extrarole performance such as helping and supportive behavior toward coworkers. Researchers have begun to study organizational justice in interpersonal connections with organizations, using social exchange theory as its foundation, and have identified it as a critical component in subordinate-manager relations (Akhtar et al., 2019). According to a meta-analysis conducted by Ahmed \& Malik, (2019), favorable treatments such as organizational rewards, favorable working conditions, and fairness received by employees are directly related to perceived organizational performance. Furthermore, organizational justice fosters favorable outcomes such as high job satisfaction, lower turnover, increased dedication, positive emotions, and improved performance. Multi-foci approach to social exchange have highlighted the importance of multiple sources of support, according to which individuals develop distinct give-and-take relationships with varying organizational goals (Nazir et al., 2018). A number of employees-organization-related studies (Khaleghkhah et al., 2018), have found a positive relationship between organizational justice and job satisfaction, performance, organizational justice, and turnover intention. Job satisfaction, innovative work behavior, learning goal orientation, core self-evaluations, and organizational 
justice are also relevant outcomes for organizational support. Furthermore, the literature shows that organizations achieve positive outcomes when employees perceive superior treatment within the organization (Rehman et al., 2019). Moreover, Psychological empowerment is defined as employees' perceptions of their level of competence, influence, and autonomy in the workplace, as well as the meaning of their job (Kadim et al., 2021). It is the process by which employees gain mastery and control over their lives and develop a critical understanding of their situation. According to Hameed Alali et al., (2019), empowered employees at work have increased personal, political, and interpersonal powers that improve their physical and mental health. However, another goal of this study is to look into the relationship between organizational justice and job satisfaction through the role of employees' psychological empowerment and organizational justice. However, understanding the work context that enables empowerment has significant practical and theoretical implications (Hong et al., 2019), but we don't know how or why. This study also looked at whether and how proactive people could be a boundary condition for the impact of organizational justice on psychological empowerment. Furthermore, it investigated how the overall process differs depending on proactive personality levels. Proactive personality refers to an individual's proclivity to take initiative in order to create a positive environment. People with a proactive personality are more likely to be able to effect positive change in the workplace, regardless of the obstacles and constraints they face (Marta et al., 2021). According to proactive personality research, proactive behavior influences meaningful changes in the workplace. Researchers contend that proactive individuals are more likely to be ready for job-related changes, given their proclivity to identify and respond to job opportunities and make changes that align with their interests at work (Haryono et al., 2019). Experiments have shown that proactive individuals can influence vocational adaptability through situations and samples. However, there is a hazy understanding of the underlying mechanisms that cause these effects. Examining these mechanisms will most likely provide future substitutes for intervention for counselors and psychologists (Hameed \& Anwar, 2018). These experts, for example, are likely to gain relatively advanced understandings of whether and how proactive employees feel psychologically empowered as a result of these types of mechanisms. Psychological empowerment is an employee's active and lively orientation to their respective role assigned at work, in which empowered employees see their work environment as something that can be shaped by their actions, which arouses their creative behavior, and it serves as a factor that transmits the impact of proactive individuals to job satisfaction. However, the purpose of this study is to investigate how contextual factors such as organizational justice can be linked to overall job satisfaction (Hamad et al., 2021). Second, psychological empowerment is regarded as an important moderator of organizational justice and job satisfaction. In addition, proactive personality moderates the relationship between organizational justice and psychological empowerment. organizational justice is one of the jobrelated attitudes that has received special attention in organizational behavior research. The current study represented an attempt to contribute to the literature in a variety of ways by establishing the proposed associations in the model. organizational justice is based on organizational support theory (DeConinck et al., 2018), which is also based on social exchange relationships and attribution methods (García-Juan et al., 2020). According to organizational support scholars, employees tend to monitor their situations and make attributions for organizations' generous behaviors. Individuals tend to personify their respective organizations and regard positive and negative treatment from organizational heads as their perception of being favored or disfavored by organizations (Qader et al., 2021). According to research in the field of organizations, there is a reciprocal relationship between individuals and organizations. As a result, rather than focusing solely on the employee side of this relationship, it is critical to consider the organizational support provided to individuals (Maan et al., 2020).

\section{Aim of the study}

The current study aimed to examine the influence of psychological empowerment and organizational justice on perceived organizational performance at public sectors in Kurdistan region of Iraq.

\section{Conceptual Framework}

\section{Research Model}

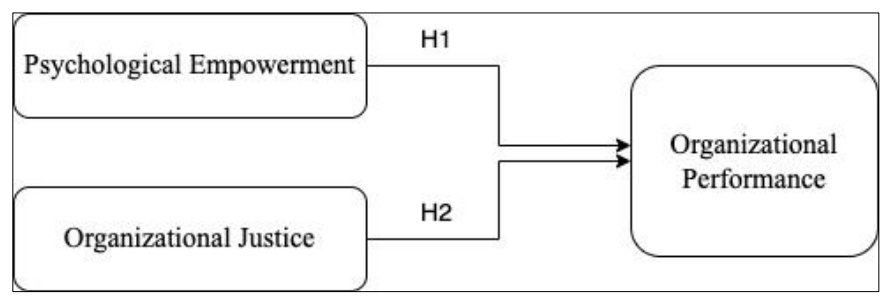

Fig.1: Research Model

\section{Research Hypotheses:}

H1: Psychological empowerment has a positive and significant influence on perceived organizational performance at public sector in Kurdistan region of Iraq. 
$\mathrm{H}$ 2: Organizational justice has a positive and significant influence on perceived organizational performance at public sector in Kurdistan region of Iraq.

\section{LITERATURE REVIEW}

\section{Psychological Empowerment}

Psychological empowerment is defined as a motivational process in which people's inherent characteristics, as well as environmental factors, influence their abilities to discover meaning, enhanced competence, and self determination required to influence their environments. The psychological empowerment focuses on the psychological state of employees who are empowered and their reaction to structural empowerment conditions. Psychological empowerment is a four-dimensional construct composed of (a) meaning, (b) competence, (c) self-determination and autonomy, and (d) impact (Suifan et al., 2020).There are related concepts of psychological empowerment presented by various researchers. Earlier research on organizational research focused on empowering as a delegation of power and authority from higher levels of management to lower levels of management. They also improve lower-level employees' access to the organization's knowledge and resources (Yogalakshmi\& Suganthi, 2020). However, in recent research, researchers such as Farooqi et al., (2019) supported the idea that this construct of psychological empowerment should be viewed from a different perspective. According to Arefinet al., (2019), these management practices of delegation of authority are one side of those practices that empower employees, but it is not a pet condition. Until recently, little research on empowerment had taken an individual perspective, focusing on the psychological experience of empowerment. Although the concept of empowerment has been discussed and used in the literature for various studies, no detailed definition has been provided. According to Tran \& Choi, (2019), this concept is rarely identified and has been taken literally. This is due to the lack of a historical and experimental context for this concept, as well as other organizational concepts. Giving others authority is what empowerment entails. Empowerment should be viewed through the lens of a redistribution model that provides power balance through trust and cooperation protection. Aggarwal et al., (2018) emphasized authority as the focal point of empowerment, allowing staff to make and exert their own decisions. According to Aggarwal et al., (2020), empowerment is defined as the mental relationships between employers and employees. It has been demonstrated that psychological empowerment is related to organizational attitudes and behaviors. The above discussion of various concepts about psychological empowerment demonstrates that it is a very important phenomenon in the field of social sciences and should be thoroughly addressed. Because empowered individuals are more loyal and sincere to the organization and positively contribute to the improvement of organizational performance (Chegini et al., 2019).

Previous theories of psychological empowerment demonstrate the significance of psychological empowerment in business and organizations. Other studies have found that psychological empowerment has a positive impact on job satisfaction, organizational justice, service quality, job performance, effectiveness, and innovative behavior. Additionally, psychological empowerment improves positive work outcomes such as psychological empowerment (Loes \& Tobin, 2020). Khalid et al., (2018) stated that psychological empowerment positively influences pschological empowerment in an empirical study. The study found that the higher the level of psychological empowerment of employees, the more motivated they are to perform well at work. Employees are also motivated to demonstrate more OJ, despite their positive feelings about psychological empowerment. Similarly, Asgari et al., (2020) investigated the relationships between organizational justice, psychological empowerment, organizational justice, job satisfaction, and OJ. According to the findings, psychological empowerment was positively related to job satisfaction, organizational justice, and pschological empowerment. Kwantes \& Bond, (2019) also conducted a study to investigate the impact of psychological empowerment on work outcomes such as Pschological empowerment. The findings revealed a significant link between psychological empowerment and OJ. Thus, when psychological empowerment acts as a moderator, there is a significant relationship between transformational psychological empowerment and OJ. Organizational justice can have a significant impact on psychological empowerment components (Cugueró-Escofet et al., 2019). According to the organizational support theory, employees develop a sense of how much the organization values their contribution and cares about their well-being. Organizational justice was a significant predictor variable of OJ (Akram et al., 2020).

\section{Organizational Justice}

Organizational justice is an important topic in the field of organizational behavior because it is meaningful to and has a significant impact on organizational members. Organizational justice refers to the perceived fairness in a variety of decision-making processes and outcomes by employees within an organization. Furthermore, 
organizational justice is defined as the extent to which organizational members believe the rewards they receive (distributive justice) and the methods and procedures used to determine the quantity of such rewards (procedural justice) are fair (Waheed et al., 2018).

OJ has been extensively researched in the fields of organizational behavior and applied psychology (AlKahtani et al., 2021). Fragkos et al., (2020) introduced the concept of OJ briefly with the goal of measuring the level of performance. OJ is based on the concept of equity theory. Employees typically perceive cognitive conflict when they believe that things or procedures are based on unfairness. According to Chung, (2018), the concept of OJ is based on three key components: process, outcomes, and interpersonal relationships. Employees, according to OJ's theory, are constantly measuring and comparing their "inputs" with their "outputs." Previous research has classified OJ into four subtypes: distributive, informational, procedural, and interpersonal. OJ, on the other hand, is broadly defined and applied in three dimensions: distributive, interactional, and procedural justice. To begin, distributive justice emphasizes the fairness of outcomes. Second, procedural justice demonstrates the fairness and consistency in rewarding procedures for all parties. Third, interactional injustice demonstrates their employer's fairness in receiving information and interpersonal treatment. OJ lays the groundwork for a healthy working environment and helps organizations retain loyal human capital. As a result, OJ benefits employees, organizations, and societies in equal measure. The existing literature has discovered links between $\mathrm{OJ}$ and job-related outcomes (for example, pay satisfaction, performance, trust, and organizational justice) in the workplace (Hamza et al., 2021). Employees who perceive injustice in the workplace may be dissatisfied with their jobs, call in sick, exhibit lower levels of justice, and eventually seek to quit. Another study discovered that performance appraisal system standards align with employees' competencies, skills, and goals to increase job satisfaction in the workplace (Lyu et al., 2019). There has been little research into how perceptions of OJ practices reduce levels of job dissatisfaction among employees in developing countries' private and public sectors. Ali et al., (2021) distinguished between two types of empowerments: physiological empowerment and structural empowerment. Structural empowerment refers to a set of practices for accessing information and learning in the workplace, whereas psychological empowerment refers to a motivational feeling based on four cognitions: competence, meaning, self-determination, and impact. Physiological empowerment occurs when organizational members or employees perceive control over their working lives, according to Farid et al., (2019), empowered employees believe that their work lives are important and that they care about what they do at work. According to researchers, physiological empowerment can increase motivation and a sense of personal control, which can lead to positive organizational and managerial outcomes in the workplace. In recent research, psychological empowerment has been used as an independent variable (Akhtar et al., 2019). Ahmed \& Malik, (2019) conducted research on the moderating effects of psychological empowerment on the relationship between organizational trust and employee engagement. As stated in the preceding discussion, no study has been discovered that investigates the interactive role of psychological empowerment on the relationship between $\mathrm{OJ}$ and the level of job dissatisfaction in either developed or developing countries.

The concept of OJ is based on the Equity Theory, which states that people compare themselves to others in terms of their outcomes and inputs, and then use ratios to assess the equity of input and output. Furthermore, theory proposes that people avoid inequitable and unjust relationships; thus, they maintain only equitable and fair relationships with one another. Employees of the firm want the relationship and resources distributed among people to be unbiased and not favor any individual or group over others (Qader et al., 2021). When an employee of a firm perceives that the ratio of his or her input and output is equal to others, the spirit of Equity Theory exists (DeConinck et al., 2018). When inequity arises as a result of under or overcompensation, it can cause stress, tension, or anger in the individual, resulting in poor performance and behavior. According to García-Juan et al., (2020) research, OJ is required for employee satisfaction and proficiency in JP. According to Fernandes and Awamleh (2006), fair treatment of employees is referred to as OJ, which typically includes three dimensions that are described as follows: procedural justice, interactional justice, and distributive justice (Maan et al., 2020).

\section{- Procedural Justice}

Procedural justice refers to the procedures that a company follows when making a decision. Suifan et al., (2020) defined procedural justice as the firm's method of implementing relevant decision-making criteria. According to Yogalakshmi\& Suganthi, (2020) research, procedures are perceived as fair when they are applied consistently over time and across people.

\section{- Interactional Justice}

The second type of OJ is Interactional Justice, which was introduced by Farooqi et al., (2019) with the goal of focusing on the quality of fairness people receive when they are treated procedurally or when procedures are 
implemented. According to Arefinet al., (2019), issues with interactional justice arise when employees are judged unfairly, treated disrespectfully, and lied to.

\section{- Distributive Justice}

According to Tran \& Choi, (2019), Distributive Fairness is an employee's perspective on how his or her outcome compares to the outcome of another employee. According to Aggarwal et al., (2018), distributive fairness is the employees' perception of how fair the actual outcome has been distributed.

\section{Organizational Performance}

After reviewing a large amount of research literature, it was discovered that organizational performance had been measured using a variety of indicators. Aggarwal et al., (2020) used perceptual measures of organizational performance, Chegini et al., (2019), used profitability ratios and liquidity ratios to measure the financial performance of the firm, (Loes \& Tobin, 2020), practiced sales based or value added in the products of the organization by each employee, and Khalid et al., (2018), used performance measured in physical form. Asgari et al., (2020), discovered in his research that there is a disadvantage to this approach because it is highly subjective for the individual to find improvements in the organization in which the individual is working as well as the individual's own performance, and collecting information about the performance of a rival firm. As a result, managers were required to develop standards to compare the performance of their own firm to the performance of previous years in order to determine the perceived performance of the firm and the performance of the individual at the same time. The current theoretical efforts on resource-based firm observation support the concept that appropriate human resource practices may be a substantial base of "competitive advantage" and claim that all valuable and productive organizational resources lead to sustainable competitive advantage. According to resource-based theory, these foundations of value are increasingly available to almost everyone somewhere and are simple to replicate, particularly when compared to complex social arrangements such as human resource systems. According to Kwantes \& Bond, (2019), good human resource management practices improve organizational performanceby improving "employee attitudes, skills, abilities, knowledge, motivation, and working patterns. Several authors in the research field have discovered that there are relationships between individuals' HRM practices and firm performance in the market. According toCugueró-Escofet et al., (2019), human resource practices were directly related to all dimensions of the firm's market performance. Perceived organizational performance is measured by employees' perceptions of their firm's performance in comparison to the firm's financial position in previous years.

Many studies have been conducted to demonstrate the number of factors that predict organizational performance. For example, Akram et al., (2020) discovered that organizational performance is significantly related to organizational justice. Similarly, Waheed et al., (2018) found that employee JP rises when they believe their organization will support them. AlKahtani et al., (2021) found that JP and organizational justice of employees are both positively and significantly correlated. Many subsequent research studies have also confirmed the positive relationship between organizational justice and organizational performance (Fragkos et al., 2020). Chung, (2018) found a significant relationship between organizational justice and employee organizational performance. Organizations can improve their performance by focusing on the needs of their employees. Employees are motivated when they believe their organization is assisting them and they reciprocate by producing high-quality results (Hamza et al., 2021). Employees increase their sense of responsibility by using their full potential to help their organization (Hameed \& Anwar, 2018). The existing research literature also suggests that there is a positive and significant relationship between organizational justice and performance (Hamad et al., 2021).

\section{Relationship Between Psychological Empowerment and Organizational Performance}

According to DeConinck et al., (2018), competency is defined as an individual's feeling that leads to good work performance. In other words, competency refers to a person's assessment of his or her ability to perform work tasks proficiently. The degree to which people care about their work is defined as meaning. The alignment of an individual's ideals or values with the value of the work is referred to as meaning. The degree to which workers have control over their work or are free to choose how to complete their tasks is defined as self-determination(Qader et al., 2021). In addition, selfdetermination refers to a person's perception of choice in initiating behaviors and making decisions at work. The degree to which people believe they have significant influence on their immediate work environments, coworkers, and the organization as a whole is referred to as impact. In fact, the impact is perceived as the extent to which the behavior is seen as making a difference in terms of achieving the task's goal. The literature describes the consequences of psychological empowerment as positive behavioral effects that lead to improved work performance. The concept of 
empowerment can be defined as explaining how and why an employee's job can act as a motivator to energize, direct, and sustain employee behaviors that are ultimately associated with both task and contextual job performance (Hamza et al., 2021). According to Ali et al., (2021), when employees feel they have control over their work, their performance improves. Many studies have found that psychological empowerment leads to increased work effectiveness, achievement and success, improved performance, justice, and satisfaction. For example, Lyu et al., (2019), investigated the effects of psychological empowerment on the management of strategic business units. According to Hall's [25] findings, psychological empowerment influenced managerial performance positively. Fulford and Enz [26] studied the extent to which self-efficacy, impact, and meaning explained employee perceptions of satisfaction, loyalty, overall work performance, level of services provided to members, and concern for others by collecting data from service employees in thirty private clubs. Furthermore, Farid et al., (2019), demonstrated that individuals who feel more meaning in their work put forth more effort and justice to their tasks, resulting in high performance.

\section{Relationship Between Organizational Justice and Organizational Performance}

According to Nazir et al., (2018), organizational justice receives a great deal of attention in managerial and psychological research. Organizational justice refers to employees' perceptions of fairness in organizational behavior. According to previous research by various researchers and scholars, there are three types of organizational justice: distributive, procedural, and interactional justice (Khaleghkhah et al., 2018). According to Rehman et al., (2019), distributive justice is a term that describes how people perceive justice based on the consequences they receive. People's perceptions of the procedures to which the consequences belong are central to procedural justice. Interactional justice, as defined by Kadim et al., (2021), is the quality of interpersonal interactions between organizational decision-makers during organizational procedures. These three dimensions of justice interact with one another to form the perceived justice for workers in the workplace. The information of distributive, procedural, and interactional justice is processed for making and revising total justice judgments, according to the theory of justice. Other attitudes such as job satisfaction, OJ, organizational justice, organizational trust, and aggressive behavior are also influenced by organizational justice, according to this theory. Perceived justice, according to Hameed Al-ali et al., (2019), is an important factor in distinguishing more empowered (psychologically) from less empowered groups. Hong et al., (2019) explained in an article discussing the past, present, and future of organizational justice that there are many variables related to organizational behavior. The research on organizational justice may be able to explain the outcome. Because it is directly related to the workplace, organizational justice is a conceptual term used in literature to explain the contribution of fairness. Most importantly, organizational justice is concerned with how employees perceive whether or not they are treated fairly in their jobs within the organization. Employees also consider how these decisions affect other variables related to work (Marta et al., 2021). According to Haryono et al., (2019), organizational justice can assist in explaining why employees react to unfair results or unsuitable procedures and interconnections.Similarly, organizational justice refers to how much one perceives the ratio between inputs (e.g., knowledge, time, experience, efforts) invested in his job and outputs (e.g., wage, recognition, compliment, job security) to be reasonable in comparison to others (Hameed \& Anwar, 2018). Organizational justice benefits members by increasing their enthusiasm for their jobs in proportion to the reasonable treatment and rewards they receive from their organizations, and their job satisfaction rises accordingly (Hamad et al., 2021).

\section{RESEARCH METHODOLOGY}

the current study applied quantitative research method to examine the influence of psychological empowerment and organizational justice on perceived organizational performance at public sector in Kurdistan region of Iraq. A questionnaire was used to collected data from the participants (employees, supervisors, and managers) from public sector in Kurdistan region of Iraq. The study aimed to gather 130 questionnaires, but only 114 questionnaires were received from the participants, therefore the sample size for the current study was 114 units to measure the influence of psychological empowerment and organizational justice on perceived organizational performance at public sector in Kurdistan region of Iraq. A questionnaire was adopted from academic sources and was distributed via printed hard copies to the participants. 


\section{ANALYSIS AND FINDINGS}

Table 1: Bartlett test and KMO

\begin{tabular}{|c|c|c|c|c|c|}
\hline \multirow[t]{2}{*}{ Variables } & \multirow[t]{2}{*}{ Number of Items } & \multirow[t]{2}{*}{$\mathrm{n}$} & \multirow[t]{2}{*}{ KMO } & \multicolumn{2}{|l|}{ Bartlett test } \\
\hline & & & & Chi-Square & Sig. \\
\hline Psychological Empowerment & 9 & 114 & \multirow[t]{3}{*}{.711} & \multirow[t]{3}{*}{2.091} & \multirow[t]{3}{*}{.000} \\
\hline Organizational Justice & 9 & 114 & & & \\
\hline Organizational Performance & 12 & 114 & & & \\
\hline
\end{tabular}

As we can see in table (1), the result of KMO for all independent variables (Psychological empowerment and organizational justice), and perceived organizational performance as dependent variable $\mathrm{r}$; is .711 which is higher than .001 this indicates that the sample size used for the current study was more than adequate. Furthermore, the result of Chi-Square is 2.147 with the significant level .000 .

Table 2: Reliability Statistics

\begin{tabular}{|l|l|l|}
\hline Factors & Cronbach's Alpha & N of Items \\
\hline Psychological Empowerment & .739 & 9 \\
\hline Organizational Justice & .747 & 9 \\
\hline Organizational Performance & .756 & 12 \\
\hline
\end{tabular}

Table (2) shows the reliability statics analysis. The researcher used independent factors psychological empowerment and organizational justice) on the other hand, one dependent factor (perceived organizational performance). In terms of psychological empowerment as independent factor, the Cronbach's Alpha $=.739$ for 7 items, since $(.739<.6)$ therefore 9 questions used to measure psychological empowerment were reliable. In terms of organizational justice as independent factor, the
Cronbach's Alpha $=.747$ for 9 items, since $(.747<.6)$ therefore 9 questions used to measure organizational justice were reliable, and concerning perceived organizational performance as independent factor, the Cronbach's Alpha $=.756$ for 12 items, since $(.756<.6)$ therefore 12 questions used to measure dependent variable (perceived organizational performance) were reliable.

\section{Examine Research Hypothesis (1)}

Table 3: Correlations Analysis between psychological empowerment and perceived organizational performance

\begin{tabular}{|l|l|l|l|}
\hline Items & Pearson Correlation & Psychological empowerment & $\begin{array}{l}\text { Organizational } \\
\text { performance }\end{array}$ \\
\hline $\begin{array}{l}\text { Psychological } \\
\text { empowerment }\end{array}$ & Pearson correlation & 1 & \\
\cline { 2 - 4 } & Sig. (2-tailed) & & \\
\cline { 2 - 4 } & $\mathrm{N}$ & 114 & \\
\hline \multirow{2}{*}{$\begin{array}{l}\text { Organizational } \\
\text { performance }\end{array}$} & Pearson Correlation & $.722^{* *}$ & 1 \\
\cline { 2 - 4 } & Sig. (2-tailed) & .000 & 104 \\
\cline { 2 - 4 } & $\mathrm{N}$ & 114 & \\
\hline
\end{tabular}

**. Correlation is significant at the 0.01 level (2-tailed).

As seen in the above table, the Pearson Correlation between psychological empowerment and perceived organizational performance $=.722 * *$ (Correlation is significant at the 0.01 level, 2-tailed), therefore there is a strong positive correlation between psychological empowerment and perceived organizational performance at public sector in Kurdistan region of Iraq. 
Table 4: Model Summary between psychological empowerment and perceived organizational performance

\begin{tabular}{|l|l|l|l|l|}
\hline Model & R & R Square & Adjusted R Square & Std. Error of the Estimate \\
\hline 1 & $.801 \mathrm{a}$ & .719 & .727 & .21029 \\
\hline
\end{tabular}

Table (4), shows the value of $\mathrm{R}$ square $=.719$, which indicates that $72 \%$ of the variables have been explained.

Table 5: ANOVA between psychological empowerment and perceived organizational performance

\begin{tabular}{|l|l|l|l|l|l|l|}
\hline Model & & Sum of squares & Df & Mean Square & F & Sig. \\
\hline & Regression & 39.901 & 5 & 11.9122 & 101.212 & $.000 \mathrm{~b}$ \\
\hline 1 & Residual & 3.912 & 101 & .039 & & \\
\hline & Total & 43.813 & 106 & & & \\
\hline
\end{tabular}

a. Dependent Variable: Perceived organizational performance

b. Predictors: (Constant), Psychological empowerment

Table (5) shows the value of $\mathrm{F}$ for four independent factors and a dependent factor is 101.212>1 which indicates there is a significant association between independent factor

(psychological empowerment) and dependent factor (Perceived organizational performance).

Table 6: Simple Regression Analysis between psychological empowerment and perceived organizational performance

\begin{tabular}{|l|l|l|l|l|l|l|}
\hline Model & & \multicolumn{2}{|l|}{ Unstandardized Coefficients } & $\begin{array}{l}\text { Standardized } \\
\text { Coefficients }\end{array}$ & $\mathrm{t}$ & Sig. \\
\hline 1 & & $\mathrm{~B}$ & Std. Error & Beta & & \\
\cline { 2 - 7 } & (Constant) & .299 & .137 & & 1.812 & .12 \\
\cline { 2 - 7 } & $\begin{array}{l}\text { Psychological } \\
\text { empowerment }\end{array}$ & .714 & .041 & .721 & .819 & .000 \\
\hline
\end{tabular}

a. Dependent Variable: Perceived organizational performance

As seen the result of simple regression analysis, the value B for psychological empowerment factor is .714 $(.714>0.01)$ therefore first research hypothesis was supported which stated that psychological empowerment

\section{Examine Research Hypothesis (2)}

Table 7: Correlation Analysis between organizational justice and perceived organizational performance

\begin{tabular}{|l|l|l|l|}
\hline Items & Pearson Correlation & Organizational Justice & $\begin{array}{l}\text { Organizational } \\
\text { performance }\end{array}$ \\
\hline \multirow{4}{*}{$\begin{array}{l}\text { Organizational } \\
\text { Justice }\end{array}$} & Pearson correlation & 1 & \\
\cline { 2 - 4 } & Sig. (2-tailed) & & \\
\cline { 2 - 4 } & $\mathrm{N}$ & 114 & \\
\hline \multirow{2}{*}{$\begin{array}{l}\text { Organizational } \\
\text { performance }\end{array}$} & Pearson Correlation & $.701 * *$ & 1 \\
\cline { 2 - 4 } & Sig. (2-tailed) & .000 & 104 \\
\cline { 2 - 4 } & $\mathrm{N}$ & 114 & \\
\hline
\end{tabular}

**. Correlation is significant at the 0.01 level (2-tailed).

This article can be downloaded from here: $\underline{w w w . i j a e m s . c o m}$ 
As seen in the above table, the Pearson Correlation between organizational justice and perceived organizational performance $=.701 * *$ (Correlation is significant at the 0.01 level, 2-tailed), therefore there is a strong positive correlation between organizational justice and perceived organizational performance at public sector in Kurdistan region of Iraq.

Table 8: Model Summary between organizational justice and perceived organizational performance

\begin{tabular}{|l|l|l|l|l|}
\hline Model & R & R Square & Adjusted R Square & Std. Error of the Estimate \\
\hline 1 & .792 & .699 & .708 & .29121 \\
\hline
\end{tabular}

Table (8), shows the value of $\mathrm{R}$ square $=.699$, which indicates that $70 \%$ of the variables have been explained.

Table 9: ANOVA between organizational justice and perceived organizational performance

\begin{tabular}{|l|l|l|l|l|l|l|}
\hline Model & & Sum of squares & Df & Mean Square & F & Sig. \\
\hline & Regression & 33.191 & 3 & 10.121 & 122.321 & $.000 \mathrm{~b}$ \\
\hline 1 & Residual & 2.899 & 94 & .029 & & \\
\hline & Total & 36.09 & 97 & & & \\
\hline
\end{tabular}

a. Dependent Variable: Perceived organizational performance

b. Predictors: (Constant), Organizational Justice

Table (9) shows the value of $\mathrm{F}$ for four independent factors and a dependent factor is $122.321>1$ which indicates there is a significant association between independent factor (organizational justice) and dependent factor (Perceived organizational performance).

Table 10: Simple Regression Analysis between organizational justice and perceived organizational performance

\begin{tabular}{|l|l|l|l|l|l|l|}
\hline Model & & \multicolumn{2}{|l|}{ Unstandardized Coefficients } & $\begin{array}{l}\text { Standardized } \\
\text { Coefficients }\end{array}$ & $\mathrm{t}$ & Sig. \\
\hline \multirow{3}{*}{1} & & $\mathrm{~B}$ & Std. Error & Beta & & \\
\cline { 2 - 8 } & (Constant) & .231 & .104 & & 1.722 & .009 \\
\cline { 2 - 8 } & Organizational justice & .699 & .039 & .704 & .901 & .000 \\
\hline
\end{tabular}

a. Dependent Variable: Perceived organizational performance

As seen the result of simple regression analysis, the value B for organizational justice factor is .699 (.699>0.01) therefore second research hypothesis was supported which stated that organizational justice has a positive and significant influence on perceived organizational performance at public sector in Kurdistan region of Iraq.

\section{CONCLUSION}

The study aimed to investigate the influence of psychological empowerment and organizational justice on perceived organizational performance at public sectors in Kurdistan region of Iraq. In order to improve organizational performance, organizations should increase their spending on research and development. The research provided empirical evidence regarding the role of psychological empowerment and organizational justice and its influence of perceived organizational performance. The study attempted to offer leaders in the KRG research public sector a strategy that improves the psychological empowerment of staff in order to maintain employees' high sense of citizenship behavior to the public sector, which in turn will improve KRG's performance.The study developed two research hypotheses to measure the current study. The findings revealed that the first research hypothesis was supported which stated that psychological empowerment has a positive and significant influence on perceived organizational performance at public sector in 
Kurdistan region of Iraq, furthermore the second research hypothesis was supported which stated that organizational justice has a positive and significant influence on perceived organizational performance at public sector in Kurdistan region of Iraq.

However, it was found that the highest value was for the psychological empowerment effect on perceived organizational performance. The future of organizations is dependent on their employees' work behavior. Organizational top management should maintain a healthy working environment by promoting OJ practices and empowering employees to increase their levels of motivation and performance in the workplace. To ensure and maintain an optimal level of job satisfaction, top management in the public sector should emphasize justice practices in the workplace. According to the findings of this study, OJ such as distributive, interactional, and procedural justice can reduce job dissatisfaction in the workplace. Furthermore, psychological empowerment programs can play an important role in motivating employees to face workplace business changes.This research has scholarly ramifications. The conventional vertical relationship between psychological empowerment and organizational justice, psychological empowerment and organizational justice, has been well documented. However, the relationship between horizontal shared psychological empowerment and organizational justice, as well as psychological empowerment and organizational justice, has received little attention. Notably, the questionnaire items for this study were developed based on the literature and surveyed corporate practitioners. Organizational justice is required to achieve high performance in a company. It is advisable to identify and distribute various factors that can improve organizational justice to members. This study also demonstrated the important relationship between shared psychological empowerment and psychological empowerment and organizational justice, which will serve as a guideline for future organizational justice. Despite the implications mentioned above, this study has limitations. Except for organizational justice, which is a variable involving organizational effectiveness, it failed to take into account variables such as job performance, pschological empowerment, and organizational performance. Future research should further analyze and consider various variables, as well as compare local findings to those from other countries.

\section{LIMITATIONS AND FUTURE DIRECTIONS}

There were numerous limitations to the research while it was being conducted. The first is a sample size limitation. A large enough sample size should be considered for more accurate results. Second, respondents have a lack of understanding of the concepts raised in the questions. Third, organizational performance was measured based on employee perception, which may result in biased and erroneous results. This research was carried out in a developing country where organizations were not fully implementing management policies and practices discussed in the literature. In the future, much attention will be required to test such concepts in other fields of industry. The current study was conducted in the public sectoring sector. Future research should include other industries such as services and manufacturing and private sectors.

\section{REFERENCES}

[1] Aggarwal, A., Chand, P. K., Jhamb, D., \& Mittal, A. (2020). Leader-member exchange, work engagement, and psychological withdrawal behavior: the mediating role of psychological empowerment. Frontiers in Psychology, 11, 423.

[2] Aggarwal, A., Dhaliwal, R. S., \& Nobi, K. (2018). Impact of structural empowerment on organizational commitment: the mediating role of women's psychological empowerment. Vision, 22(3), 284-294.

[3] Ahmed, N., \& Malik, B. (2019). Impact of psychological empowerment on job performance of teachers: Mediating role of psychological well-being. Review of Economics and Development Studies, 5(3), 451-460.

[4] Akhtar, M. W., Syed, F., Husnain, M., \& Naseer, S. (2019). Person-organization fit and innovative work behavior: The mediating role of perceived organizational support, affective commitment and trust. Pakistan Journal of Commerce and Social Sciences (PJCSS), 13(2), 311-333.

[5] Akram, T., Lei, S., Haider, M. J., \& Hussain, S. T. (2020). The impact of organizational justice on employee innovative work behavior: Mediating role of knowledge sharing. Journal of Innovation \& Knowledge, 5(2), 117-129.

[6] Ali, B. J., Saleh, P. F., Akoi, S., Abdulrahman, A. A., Muhamed, A. S., Noori, H. N., \& Anwar, G. (2021, May). Impact of Service Quality on the Customer Satisfaction: Case study at Online Meeting Platforms. In Ali, BJ, Saleh, Akoi, S., Abdulrahman, AA, Muhamed, AS, Noori, HN, Anwar, G.(2021). Impact of Service Quality on the Customer Satisfaction: Case study at Online Meeting Platforms. International journal of Engineering, Business and Management (Vol. 5, No. 2, pp. 65-77).

[7] AlKahtani, N., Iqbal, S., Sohail, M., Sheraz, F., Jahan, S., Anwar, B., \& Haider, S. (2021). Impact of employee empowerment on organizational commitment through job satisfaction in four and five stars hotel industry. Management Science Letters, 11(3), 813-822. 
[8] Arefin, M. S., Alam, M. S., Islam, M. R., \& Rahaman, M. (2019). High-performance work systems and job engagement: The mediating role of psychological empowerment. Cogent Business \& Management, 6(1), 1664204.

[9] Asgari, A., Mezginejad, S., \& Taherpour, F. (2020). The role of leadership styles in organizational citizenship behavior through the mediation of perceived organizational support and job satisfaction. Innovar, 30(75), 87-98.

[10] Chegini, Z., Janati, A., Asghari-Jafarabadi, M., \& Khosravizadeh, O. (2019). Organizational commitment, job satisfaction, organizational justice and self-efficacy among nurses. Nursing Practice Today, 6(2), 86-93.

[11] Chung, Y. W. (2018). Workplace ostracism and workplace behaviors: A moderated mediation model of perceived stress and psychological empowerment. Anxiety, Stress, \& Coping, 31(3), 304-317.

[12] Cugueró-Escofet, N., Ficapal-Cusí, P., \& Torrent-Sellens, J. (2019). Sustainable human resource management: How to create a knowledge sharing behavior through organizational justice, organizational support, satisfaction and commitment. Sustainability, 11(19), 5419.

[13] DeConinck, J. B., Moss, H. K., \& Deconinck, M. B. (2018). The relationship between servant leadership, perceived organizational support, performance, and turnover among business to business salespeople. Global J Management and Marketing, 2(1), 38-52.

[14] Farid, T., Iqbal, S., Ma, J., Castro-González, S., Khattak, A., \& Khan, M. K. (2019). Employees' perceptions of CSR, work engagement, and organizational citizenship behavior: The mediating effects of organizational justice. International journal of environmental research and public health, 16(10), 1731.

[15] Farooqi, M. T. K., Ahmed, S., \& Ashiq, I. (2019). Relationship of Perceived Organizational Support with Secondary School Teachers' Performance. Bulletin of Education and Research, 41(3), 141-152.

[16] Fragkos, K. C., Makrykosta, P., \& Frangos, C. C. (2020). Structural empowerment is a strong predictor of organizational commitment in nurses: A systematic review and meta-analysis. Journal of Advanced Nursing, 76(4), 939-962.

[17] García-Juan, B., Escrig-Tena, A. B., \& Roca-Puig, V. (2020). Psychological empowerment: Antecedents from goal orientation and consequences in public sector employees. Review of Public Personnel Administration, 40(2), 297-326.

[18] Hamad, H. A., Qader, K. S., Gardi, B., Abdalla, P., Hamza, D., \& Anwar, G. (2021). The essential variables to consider before investing in financial markets during Covid-19.

[19] Hameed Al-ali, A., Khalid Qalaja, L., \& Abu-Rumman, A. (2019). Justice in organizations and its impact on Organizational Citizenship Behaviors: A multidimensional approach. Cogent Business \& Management, 6(1), 1698792.

[20] Hameed, A. A., \& Anwar, K. (2018). Analyzing the Relationship between Intellectual Capital and Organizational Performance: A Study of Selected Private
Banks in Kurdistan. International Journal of Social Sciences \& Educational Studies, 4(4), 39.

[21] Hamza, P. A., Hamad, H. A., Qader, K. S., Gardi, B., \& Anwar, G. (2021). Management of outsourcing and its relationship with hotels' performance: An empirical analysis of selected hotels in Erbil. International Journal of Advanced Engineering Research and Science, 8, 10.

[22] Haryono, S., Ambarwati, Y. I., \& Saad, M. S. M. (2019). Do organizational climate and organizational justice enhance job performance through job satisfaction? A study of Indonesian employees. Academy of Strategic Management Journal, 18(1), 1-6.

[23] Hong, E., Jeong, Y., \& Downward, P. (2019). Perceived organizational support, internal motivation, and workfamily conflict among soccer referees. Managing Sport and Leisure, 24(1-3), 141-154.

[24] Kadim, J. R., Sabti, Y. M., Ali, G., Abbas, Y. A., \& Shliot, S. M. (2021). The Effect of Applying Organizational Justice on Job Burnout (An Applied Study in the Municipality of Samawah). South Asian Journal of Social Sciences and Humanities, 2(2), 135-155.

[25] Khaleghkhah, A., Nemati, V., Ebrahimi, S., \& Moradi, B. (2018). The relationship between psychological empowerment and career enthusiasm in predicting entrepreneurship from staff viewpoint in Shahid Beheshti University of Medical Sciences. Journal of Health, 9(4), 432-441.

[26] Khalid, S., Rehman, C. A., \& Muqadas, F. (2018). Exploring the mediating role of affective commitment on organizational justice and turnover intention. Pakistan Business Review, 19(4), 1012-1028.

[27] Kwantes, C. T., \& Bond, M. H. (2019). Organizational justice and autonomy as moderators of the relationship between social and organizational cynicism. Personality and Individual Differences, 151, 109391.

[28] Loes, C. N., \& Tobin, M. B. (2020). Organizational trust, psychological empowerment, and organizational commitment among licensed practical nurses. Nursing Administration Quarterly, 44(2), 179-187.

[29] Lyu, D., Ji, L., Zheng, Q., Yu, B., \& Fan, Y. (2019). Abusive supervision and turnover intention: Mediating effects of psychological empowerment of nurses. International Journal of Nursing Sciences, 6(2), 198203.

[30] Maan, A. T., Abid, G., Butt, T. H., Ashfaq, F., \& Ahmed, S. (2020). Perceived organizational support and job satisfaction: a moderated mediation model of proactive personality and psychological empowerment. Future Business Journal, 6(1), 1-12.

[31] Marta, I. A., Supartha, I., Dewi, I. G. A. M., \& Wibawa, I. (2021). Job enrichment, empowerment, and organizational commitment: The mediating role of work motivation and job satisfaction. The Journal of Asian Finance, Economics, and Business, 8(1), 1031-1040.

[32] Nazir, S., Qun, W., Hui, L., \& Shafi, A. (2018). Influence of social exchange relationships on affective commitment and innovative behavior: Role of perceived organizational support. Sustainability, 10(12), 4418. 
[33] Qader, K. S., Hamad, H. A., Gardi, B., Abdalla, P., Hamza, D., \& Anwar, G. (2021). The role of sophisticated accounting system in organizational planning.

[34] Rehman, W. U., Ahmad, M., Allen, M. M., Raziq, M. M., \& Riaz, A. (2019). High involvement HR systems and innovative work behaviour: the mediating role of psychological empowerment, and the moderating roles of manager and co-worker support. European Journal of work and organizational psychology, 28(4), 525-535.

[35] Suifan, T. S., Diab, H., Alhyari, S., \& Sweis, R. J. (2020). Does ethical leadership reduce turnover intention? The mediating effects of psychological empowerment and organizational identification. Journal of Human Behavior in the Social Environment, 30(4), 410-428.

[36] Tran, T. B. H., \& Choi, S. B. (2019). Effects of inclusive leadership on organizational citizenship behavior: the mediating roles of organizational justice and learning culture. Journal of Pacific Rim Psychology, 13.

[37] Waheed, A., Abbas, Q., \& Malik, O. F. (2018). 'Perceptions of performance appraisal quality'and employee innovative behavior: do psychological empowerment and 'perceptions of HRM system strength'matter?. Behavioral sciences, 8(12), 114.

[38] Yogalakshmi, J. A., \& Suganthi, L. (2020). Impact of perceived organizational support and psychological empowerment on affective commitment: Mediation role of individual career self-management. Current Psychology, 39(3), 885-899. 